\title{
Penerapan Model Antrian Multi Channel-Single Phase pada SPBU Sempu Jurong Cikarang Utara
}

\author{
Ica Hoerunisa ${ }^{1)}$ dan Sukanta ${ }^{2)}$ \\ Jurusan Teknik Industri, Fakultas Teknik, Universitas Singaperbangsa Karawang, Jl. HS. Ronggo Waluyo, \\ Telukjambe Timur Karawang Jawa Barat 41361, Indonesia \\ ${ }^{1)}$ ica.hoerunisa17078@ student.unsika.ac.id \\ ${ }^{2)}$ sukanta@staff.unsika.ac.id
}

\begin{abstract}
Abstrak. SPBU Sempu Jurong menyediakan 4 fasilitas pelayanan dan dua diantaranya fasilitas pelayanan untuk kendaraan roda dua yang memiliki antrian paling mendominasi dibandingkan dengan antrian lainnya. Antrian yang terjadi diakibatkan tidak seimbangnya jumlah fasilitas pelayanan dengan jumlah kedatangan pelanggan kendaraan roda dua. Penelitian ini bertujuan untuk meningkatkan tingkat pelayanan dengan mengetahui jumlah fasilitas pelayanan dan waktu pelayanan yang optimal pada SPBU Sempu Jurong. Dalam penelitian ini, metode yang digunakan adalah model antrian Multi Channel Single Phase dengan perhitungan secara manual dan menggunakan software POM-QM for Windows 5.2. Hasil penelitian ini menunjukkan adanya perubahan yang signifikan dengan adanya penambahan satu fasilitas pengisian bahan bakar kendaraan roda dua pada SPBU Sempu Jurong. Berdasarkan perhitungan dengan penerapan model Multi Channel Single Phase secara manual dan menggunakan POM-QM for Windows 5.2, diperoleh standar waktu pelayanan $\left(W_{q}\right)$ optimal dengan 3 fasilitas pelayanan membutuhkan waktu sebesar 0,24 menit. Hal ini menunjukkan standar waktu pelayanan (Wq) 0,24 menit sudah jauh lebih cepat dari standar waktu yang ditetapkan sebesar 0,75 menit sehingga kepuasan pelanggan akan pelayanan SPBU Sempu Jurong Cikarang Utara dapat tercapai.
\end{abstract}

Kata kunci: antrian, Multi Channel-Single Phase

\begin{abstract}
Application of Multi Channel-Single Phase Queueing Models at SPBU Sempu Jurong Cikarang Utara]. SPBU Sempu Jurong provides 4 service facilities and two of them are service facilities for two-wheeled vehicles, which have the most dominant queues compared to other queues. The queue that occurs is due to the imbalance between the number of service facilities and the number of two-wheeled vehicle customers. This study aims to increase the level of service by knowing the number of service facilities and optimal service time at SPBU Sempu Jurong. In this study, the method used is the Multi Channel Single Phase queuing model with manual calculations and using POM-QM for Windows 5.2 software. The results of this study indicate a significant change with the addition of a two-wheeled vehicle refueling facility at SPBU Sempu Jurong. Based on calculations by applying the Multi Channel Single Phase model manually and using POM-QM for Windows 5.2, the optimal standard service time $(\mathrm{Wq})$ is obtained with 3 service facilities requiring 0.24 minutes. This shows that the standard service time $(W q)$ of 0.24 minutes is much faster than the standard time set at 0.75 minutes so that customer satisfaction with services SPBU Sempu Jurong Cikarang Utara can be achieved.
\end{abstract}

Keywords: queue, Multi Channel-Single Phase.

\section{Pendahuluan}

Jumlah produksi kendaraan bermotor kian hari semakin melonjak bersamaan dengan beragamnya kebutuhan serta permintaan pelanggan yang harus terpenuhi. Pada keadaan tertentu, kebutuhan bahan bakar untuk kendaraan bermotor mengalami kenaikan serta untuk mendapatkannya terkadang memerlukan waktu yang lebih lama. Sehingga menimbulkan antrian panjang karena jumlah pelanggan yang membutuhkan bahan bakar dalam waktu yang sama lebih besar dibanding dengan ketersediaan fasilitas. Antrian yang panjang membuat pelanggan merasa kecewa sebab memerlukan waktu lebih lama lagi untuk menunggu dan masih banyak aktivitas yang harus segera dikerjakan. Antrian dapat dihindari jika pihak-pihak tertentu mampu menganalisis bagaimana waktu yang ada dapat dimanfaatkan secara optimal.

Semakin banyak konsumen maka jumlah antrian semakin memanjang hingga ke jalan raya. Umumnya, peristiwa antrian ini sering dialami oleh setiap orang dalam kehidupannya. Walaupun antrian sudah menjadi hal biasa, namun kegiatan menunggu merupakan sesuatu hal yang membosankan apalagi 


\author{
Jurnal Pendidikan dan Aplikasi Industri (UNISTEK) \\ Vol. 8 No.1 Februari 2021 \\ p- ISSN : 0126 - 4036 \\ e- ISSN : 2716 - 0416
}

dalam waktu terlalu lama. Para manajer berusaha untuk memecahkan masalah mengenai pengurangan waktu tunggu konsumen, sehingga untuk menemukan solusinya diperlukan suatu teori antrian yang paling tepat berdasarkan struktur antrian yang terjadi di lapangan (Sari, 2013).

Pada penelitian sebelumnya, yang dilakukan oleh Cut I. Setiawati dan Farah A. Budyanna (2017) menganalisis sistem antrian pada Bank BCA dengan menentukan jumlah teller yang tepat agar antrian yang terjadi dapat diminimalisir. Dengan menggunakan model antrian Multi Channel Single Phase, diperoleh jumlah teller yang tepat sebanyak 7 orang dengan waktu menunggu nasabah dalam sistem berkurang dari 63 menit menjadi 26 menit (Setiawati \& Budyanna, 2017).

Penelitian yang dilakukan oleh Supriyadi, dkk (2019) mencoba membuat sistem rekayasa antrian pada teller Bank dengan menggunakan teori antrian Multi Channel Single Phase (M/M/S), dimana terdapat 4 teller dan 1 tahap pelayanan yang dilalui nasabah dalam bertransaksi. Dari hasil penelitian tersebut, rekayasa sistem dilakukan dengan membuat 2 jalur antrian, dimana jalur pertama untuk antrian dengan kurang dari 2 transaksi yang dilayani 1 teller, dan jalur kedua untuk antrian dengan lebih dari atau sama dengan 3 transaksi yang dilayani oleh 3 teller. Analisis antrian ini mengoptimalkan pelayanan bank tanpa menambahkan fasilitas pelayanan atau teller (Supriyadi, Alfarisi, Karno, \& Cahyadi, 2019).

Dalam penelitian ini, akan mengamati sistem antrian di SPBU Sempu Jurong yang berada di Cikarang Utara. SPBU Sempu Jurong menyediakan 4 fasilitas pelayanan dan dua diantaranya fasilitas pelayanan untuk kendaraan roda dua yang memiliki antrian paling mendominasi dibandingkan dengan antrian lainnya. Antrian yang terjadi diakibatkan tidak seimbangnya jumlah fasilitas pelayanan dengan jumlah kedatangan pelanggan kendaraan roda dua. Banyak pelanggan yang menunggu terlalu lama dan merasa kepanasan sehingga pelanggan tidak puas akan pelayanan yang diberikan SPBU Sempu Jurong. Apabila antrian terus memanjang, maka harus diatasi dengan mengubah kecepatan pelayanan ataupun menambah fasilitas pelayanan (Basuki, 2018). Untuk mengatasi permasalahan antrian tersebut, dibutuhkan suatu analisis model antrian Multi Channel-Single Phase di SPBU Sempu Jurong secara manual dan dengan menggunakan software POM-QM for Windows 5.2.

Tujuan dilakukan penelitian ini adalah untuk meningkatkan kinerja pelayanan dengan mengetahui jumlah fasilitas pelayanan dan waktu pelayanan yang optimal pada SPBU Sempu Jurong. Penelitian ini memiliki batasan masalah diantaranya pengamatan dilakukan pada fasilitas pengisian bahan bakar kendaraan roda dua, pengamatan dilakukan selama 3 hari yaitu Kamis (10/12/2020), Jumat (11/12/2020) dan Sabtu (12/12/2020) serta hanya dilakukan pada jam 07.00-08.00 WIB, jam 16.00-17.00 WIB dan jam 19.00-20.00 WIB, yang bertujuan agar hasil analisis dapat diterapkan pada berbagai situasi dan memberikan saran yang bermanfaat bagi SPBU Sempu Jurong dalam menyelesaikan masalah antrian yang terjadi.

\section{Bahan dan Metode Antrian}

Jay Heizer dan Barry Render (2006) mendefinisikan suatu antrian sebagai sekumpulan orang ataupun barang yang berada di sebuah deretan menanti pelayanan atau meliputi bagaimana suatu perusahaan mampu memastikan jumlah fasilitas serta waktu yang optimal agar dapat memenuhi pelayanan pelanggan dengan efektif. Teori antrian memiliki fungsi untuk mengamati peristiwa dalam sebuah antrian dengan menghitung beberapa kinerja yang digunakan (Febrianti, 2020). Antrian merupakan suatu kondisi pelayanan yang mana waktu kedatangan melebihi waktu pelayanan (Widiantono \& Sukmono, 2017).

Sebuah antrian terjadi karena permintaan pelanggan terhadap pelayanan melampaui dari kemampuan dan jumlah fasilitas pelayanannya, sehingga mengakibatkan pelanggan harus menunggu dan tidak bisa segera mendapatkan layanan karena kesibukan aktivitas petugasnya (Nengsih \& Yustanti, 2017). Antrian terjadi di beberapa tempat yang banyak dibutuhkan oleh orang-orang seperti Stasiun Pengisian Bahan Bakar Umum (SPBU) (Hanggara \& Putra, 2020). Pelanggan memasuki area pelayanan dan berkumpul membentuk antrian menunggu sampai mendapatkan pelayanan dengan berdasarkan aturan disiplin antrian hingga akhirnya meninggalkan area pelayanan (Permatasari \& Suryowati, 2020).

Menurut Mulyono, (2004) terdapat beberapa komponen dasar dalam sistem antrian yaitu sebagai berikut:

1. Komponen kedatangan

Antrian sangat berkaitan dengan kedatangan, contohnya orang atau motor yang dilayani. Kedatangan dapat disebut juga sebagai suatu input. Proses input atau masukan meliputi sumber kedatangan atau asal kemunculan dengan jumlah tak terbatas dan terjadi secara acak ataupun dengan jadwal tertentu.

2. Komponen pelayanan

Pada pelayanan di sebuah sistem antrian terdiri dari satu atau beberapa pelayanan/fasilitas pelayanan serta memiliki jumlah tahapan pelayanan. Selain itu, proses pelayanan terkadang terjadi secara acak.

3. Komponen antri

Bagian utama dari sebuah sistem antrian yaitu komponen antri. Disiplin antrian adalah suatu 


\author{
Jurnal Pendidikan dan Aplikasi Industri (UNISTEK) \\ Vol. 8 No.1 Februari 2021 \\ p- ISSN : 0126 - 4036 \\ e- ISSN : 2716 - 0416
}

pedoman keputusan yang mendeskripsikan bagaimana pelanggan akan dilayani terlebih dahulu Apabila antrian tidak terjadi, maka terdapat pelayanan yang menganggut atau kelebihan jumlah fasilitas pelayanan (Oktrima, 2017).

Adapun proses antrian dapat dijelaskan pada gambar di bawah ini.

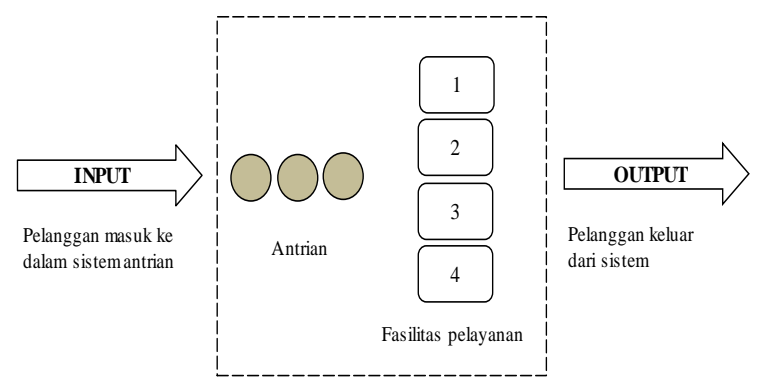

Gambar 1. Model Antrian

\section{Struktur Antrian}

Terdapat empat struktur model antrian berdasarkan pelayanannya seperti yang dijelaskan oleh Siswanto (2007) diantaranya adalah:

1. Model Single Channel Single Phase

Model ini hanya memiliki satu fasilitas pelayanan dan satu tahapan saja. Contohnya adalah mengantri di tempat dokter gigi, pembayaran di kasir Toko Beras Agung.

\section{Model Single Channel Multi Phase}

Model ini pada sistemnya terdapat satu fasilitas yang beroperasi dengan beberapa tahapan berurut. Contohnya adalah tempat mencuci kendaraan roda empat, tempat pengecatan mobil.

\section{Model Multi Channel-Single Phase}

Pada model ini memiliki terdapat beberapa fasilitas ataupun sarana layanan yang diikuti oleh satu tahap pelayanan. Contohnya adalah mengantri di SPBU, mengantri di Bank dengan beberapa teller, pembayaran di Tokma dengan beberapa kasir.

\section{Model Multi Channel-Multi Phase}

Model ini menerapkan suatu pelayanan yang memiliki banyak fasilitas pelayanan dengan beberapa tahap. Contohnya seperti pelayanan di sebuah klinik, registrasi mahasiswa baru dan sebagainya (Saputra, Irawan, \& Ilhamsyah, 2017).

\section{POM-QM for Windows 5.2}

POM-QM for Windows adalah sebuah fitur yang dirancang untuk mengelola perhitungan dalam mengambil keputusan suatu permasalahan. Langkahlangkah menggunakan POM-QM for Windows 5.2 untuk menyelesaikan masalah antrian adalah sebagai berikut:

1. Buka software POM-QM for Windows 5.2

2. Klik Module, kemudian pilih Waiting Lines

3. Klik File dan pilih New, kemudian pilih M/M/s

4. Isi bagian Title dengan judul penyelesaian masalah. Kemudian pada bagian Cost Analysis, pilih No Costs setelah itu klik $O K$.

5. Isi tabel Arrival rate (lambda), Service rate ( $m u$ ) dan Number of servers sesuai dengan data yang telah diperoleh. Kemudian pilih satuan waktu pada bagian Time unit.

6. Kemudian klik Solve.

Penelitian yang dilakukan merupakan penelitian kuantitatif deskriptif yang bertujuan untuk menjelaskan suatu fenomena saat sekarang yang terjadi dalam lingkungan sekitar (Raharjo \& Nurhajati, 2018). Penelitian ini menggunakan data primer yang diperoleh dengan wawancara dan observasi langsung mengenai banyaknya kendaraan roda dua dan waktu yang digunakan selama mengisi bahan bakar umum serta data sekunder melalui arsip SPBU Sempu Jurong. Adapun tahapan penelitian dijelaskan pada gambar di bawah ini.

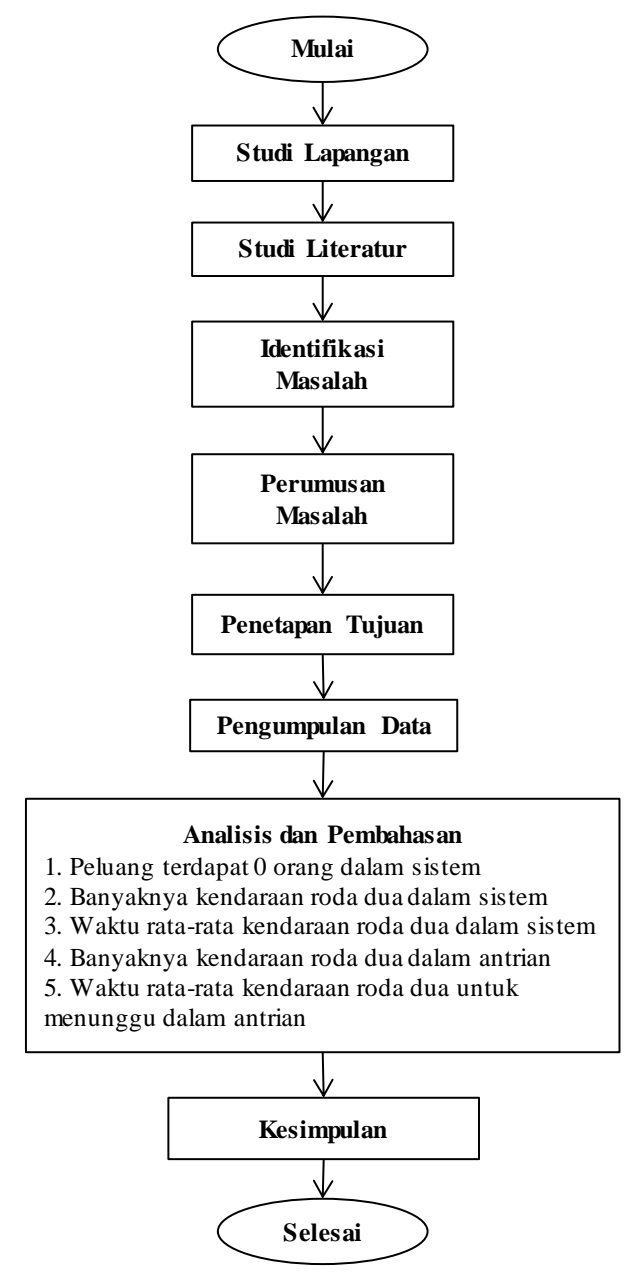

Gambar 2. Flowchart Penelitian

Dalam proses pelayanan SPBU Sempu Jurong Cikarang Utara menerapkan struktur model antrian banyak jalur-satu tahap, yang artinya SPBU Sempu 


\author{
Jurnal Pendidikan dan Aplikasi Industri (UNISTEK) \\ Vol. 8 No.1 Februari 2021 \\ p- ISSN : 0126 - 4036 \\ e- ISSN : 2716 - 0416
}

Jurong memiliki lebih dari satu fasilitas pelayanan serta melalui satu tahapan pelayanan saja. Heizer dan Render (2006) merumuskan model matematis untuk mengoptimalkan proses pelayanan antrian yang dapat digunakan pada SPBU Sempu Jurong dengan model $\mathrm{M} / \mathrm{M} / \mathrm{S}$ diantaranya adalah (Manalu \& Palandeng, 2019) :

\begin{tabular}{cc}
\hline Periode & $\begin{array}{c}\text { Tingkat Kedatangan } \\
\text { Kendaraan Roda Dua }\end{array}$ \\
\hline $07.00-08.00$ & 138 \\
$16.00-17.00$ & 150 \\
$19.00-20.00$ & 146 \\
\hline Total & 434 \\
\hline
\end{tabular}

1. Peluang 0 orang atau tidak terdapat orang dalam sistem $\left(\mathrm{P}_{\mathrm{o}}\right)$

$$
P_{0}=\frac{1}{\left[\sum_{N=0}^{M-1} \frac{1}{n !}\left(\frac{\lambda}{\mu}\right)^{n}\right]+\frac{1}{M !}\left(\frac{\lambda}{\mu}\right)^{M} \frac{M \mu}{M_{H}-\lambda}}
$$

2. Jumlah kendaraan roda dua dalam sistem $\left(\mathrm{L}_{\mathrm{s}}\right)$

$$
L_{g}=\frac{\lambda p\left(\frac{\lambda}{\mu}\right)^{M}}{(M-1)(M \mu-\lambda)^{2}} P_{0}+\frac{\lambda}{\mu}
$$

3. Waktu rata-rata kendaraan roda dua menunggu dalam sistem $\left(\mathrm{W}_{\mathrm{s}}\right)$

$$
W_{g}=\frac{L_{s}}{\lambda}
$$

4. Jumlah pelanggan rata-rata dalam antrian $\left(\mathrm{L}_{\mathrm{q}}\right)$

$$
L_{q}=L_{s}-\frac{\lambda}{\mu}
$$

5. Waktu rata-rata kendaraan roda dua menunggu dalam antrian $\left(\mathrm{W}_{\mathrm{q}}\right)$

$$
W_{q}=\frac{L_{q}}{\lambda}
$$

\section{Hasil dan Pembahasan}

Struktur sistem pelayanan pada SPBU Sempu Jurong Cikarang Utara dapat dijelaskan pada Gambar 3 berikut ini.

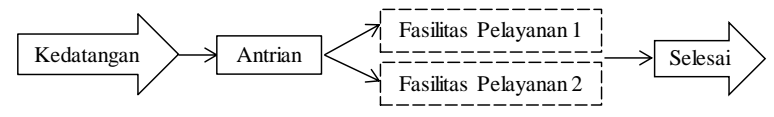

Gambar 3. Struktur Sistem Pelayanan SPBU Sempu Jurong

Tabel 1. Data Kedatangan Kendaraan Roda Dua

\begin{tabular}{cccc}
\hline \multirow{2}{*}{ No. Hari\&Tanggal } & Periode & $\begin{array}{c}\text { Jumlah } \\
\text { Kedatangan } \\
\text { (Kendaraan } \\
\text { Roda Dua) }\end{array}$ \\
\hline \multirow{2}{*}{1} & Kamis & $07.00-08.00$ & 31 \\
\cline { 3 - 4 } & $10 / 12 / 2020$ & $16.00-17.00$ & 54 \\
\cline { 3 - 4 } & Jumat & $19.00-20.00$ & 27 \\
\hline 2 & $11 / 12 / 2020$ & $07.00-08.00$ & 63 \\
\cline { 3 - 4 } & & \multicolumn{3}{c}{$16.00-17.00$} & 38 \\
\cline { 3 - 4 } & & \multicolumn{2}{c}{ Jurnal Pendidik }
\end{tabular}

\begin{tabular}{lccc}
3 & Sabtu & $07.00-08.00$ & 44 \\
\cline { 3 - 4 } & $12 / 12 / 2020$ & $16.00-17.00$ & 58 \\
\cline { 2 - 3 } & $19.00-20.00$ & 61 \\
\hline
\end{tabular}

\section{Menentukan Rata-rata Tingkat Kedatangan Per $\operatorname{Jam}(\lambda)$}

Tingkat kedatangan kendaraan roda dua per jamnya dapat dicari dengan membagi total jumlah kedatangan kendaraan roda dua pada waktu tertentu dengan total hari pengamatan.

$$
\lambda=\frac{\text { jumlah pelanggan pada jam tertentu }}{\text { total hari pengamatan }}
$$

Tabel 2. Rata-rata Tingkat Kedatangan Kendaraan Roda Dua

\section{Menentukan Tingkat Pelayanan Pelanggan $(\boldsymbol{\mu})$}

Tingkat pelayanan adalah tingkat kemampuan petugas untuk melayani dan menyelesaikan pengisian bahan bakar dalam setiap kedatangan kendaraan roda dua. Standar waktu pelayanan yang telah ditetapkan pihak manajemen melalui Standard Operating Procedure adalah 45 detik.

Standar waktu pelayanan $=\frac{45 \text { detik }}{60 \text { detik }}=0,75$ menit

Sehingga tingkat pelayanan di SPBU Sempu Jurong dapat dicari dengan cara:

$$
\begin{aligned}
\text { Tingkat pelayanan }(\mu) & =\frac{1 \text { jam }}{\text { Standarwaktu pelayanan }} \\
\text { Tingkat pelayanan }(\mu) & =\frac{60 \text { menit }}{0,75 \text { menit }} \\
\text { Tingkat pelayanan }(\mu) & =80 \text { kendaraan } / \mathrm{jam}
\end{aligned}
$$

\section{Menentukan Probabilitas Terdapat 0 Orang dalam Sistem}

Tabel 3. Probabilitas0 Orang atau Tidak Ada Orang dalam Sistem

\begin{tabular}{cc}
\hline Periode Waktu & $\begin{array}{c}\text { Probabilitas 0 orang } \\
\text { dalam sistem }\end{array}$ \\
\hline $07.00-08.00$ & 0,073826 \\
$16.00-17.00$ & 0,032258 \\
$19.00-20.00$ & 0,045752 \\
\hline
\end{tabular}

\section{Menentukan Banyaknya Kendaraan Roda Dua dalam Sistem}

Banyaknya kendaraan roda dua dalam sistem adalah jumlah kendaraan roda dua yang menunggu dan sedang dilayani oleh fasilitas pelayanan.

1. $\mathrm{L}_{\mathrm{s}}$ saat $07.00-08.00$

$$
\begin{aligned}
& \mathrm{L}_{s}=\frac{139 \times 80\left(\frac{1398}{80}\right)^{2}}{(2-1) !(2 \times 80-139)^{2}} \times 0,073826+\frac{139}{80} \\
& L_{g}=\frac{22850,9}{484} \times 0,073826+1,725=6,7356 \\
& L_{g}=7 \text { kendaraan }
\end{aligned}
$$

2. $\mathrm{L}_{\mathrm{s}}$ saat $16.00-17.00$ 


$$
\begin{aligned}
& \mathrm{L}_{g}=\frac{150 \times 80\left(\frac{150}{80}\right)^{2}}{(2-1) !(2 \times 80-150)^{2}} \times 0,032258+\frac{150}{80} \\
& L_{g}=\frac{418)^{2}}{100} \times 0,032258+1,875=15,4838 \\
& L_{g}=15 \text { atau } 16 \text { kendaraan }
\end{aligned}
$$

3. $\mathrm{L}_{\mathrm{s}}$ saat $19.00-20.00$

$$
\begin{aligned}
& \mathrm{L}_{g}=\frac{146 \times 80\left(\frac{146}{80}\right)^{2}}{(2-1) !(2 \times 80-146)^{2}} \times 0,045752+\frac{146}{80} \\
& L_{g}=\frac{\left(28901_{s}\right]}{196} \times 0,045752+1,825=10,9053 \\
& L_{g}=11 \text { kendaraan }
\end{aligned}
$$

\section{Menentukan Waktu yang Digunakan Kendaraan Roda Dua dalam Sistem}

Waktu yang digunakan kendaraan roda dua dalam sistem dimulai dari kendaraan roda dua memasuki area SPBU, mulai mengantri, sedang dilayani sampai meninggalkan area SPBU.

1. $\mathrm{W}_{\mathrm{s}}$ saat $07.00-08.00$

$$
W_{s}=\frac{6,7956}{198}=0,0488 \mathrm{jam}=2,93 \text { menit }
$$

2. $\mathrm{W}_{\mathrm{s}}$ saat $16.00-17.00$

$$
W_{s}=\frac{15,4989}{150}=0,1032 \mathrm{jam}=6,19 \text { menit }
$$

3. $\mathrm{W}_{\mathrm{s}}$ saat $19.00-20.00$

$$
W_{s}=\frac{10,905 \mathrm{a}}{146}=0,0747 \mathrm{jam}=4,48 \text { menit }
$$

\section{Menentukan Banyaknya Kendaraan Roda Dua dalam Antrian}

Banyaknya kendaraan roda dua dalam antrian ialah banyaknya kendaraan roda dua yang mengantri untuk dilayani oleh fasilitas pelayanan.

1. $\mathrm{L}_{\mathrm{q}}$ saat $07.00-08.00$

$$
L_{q}=6,7358-\frac{198}{80}=5,0108 \approx 5 \text { kendaraan }
$$

2. $\mathrm{L}_{\mathrm{q}}$ saat $16.00-17.00$

$$
L_{q}=15,4838-\frac{150}{80}=13,6088 \approx 14 \text { kendaraan }
$$

3. $\mathrm{L}_{\mathrm{q}}$ saat $19.00-20.00$

$L_{q}=10,9053-\frac{146}{80}=9,0803 \approx 9$ kendaraan

Dari perhitungan diatas, terlihat bahwa rata-rata kendaraan roda roda menunggu dalam antrian terpanjang terjadi pada jam 16.00-17.00 sekitar 14 kendaraan.

\section{Menentukan Waktu Kendaraan Roda Dua yang Menunggu dalam Antrian}

Waktu kendaraan roda dua menunggu dalam antrian adalah rata-rata waktu yang digunakan oleh kendaraan roda dua saat menunggu dilayani.
1. $\mathrm{W}_{\mathrm{q}}$ saat $07.00-08.00$

$$
W_{\mathrm{q}}=\frac{5,0108}{198}=0,0363 \mathrm{jam}=2,18 \text { menit }
$$

2. $\mathrm{W}_{\mathrm{q}}$ saat $16.00-17.00$

$$
W_{\mathrm{q}}=\frac{1 \mathrm{a}, 609 \mathrm{~g}}{150}=0,0907 \mathrm{jam}=5,44 \text { menit }
$$

3. $\mathrm{W}_{\mathrm{q}}$ saat $19.00-20.00$

$W_{q}=\frac{9,0803}{146}=0,0622$ jam $=3,73$ menit

Hasil perhitungan model antrian Multi Channel Single Phase menggunakan software POM-QM for Windows 5.2 dapat dilihat pada gambar di bawah ini.

1. Hasil perhitungan untuk jam 07.00-08.00

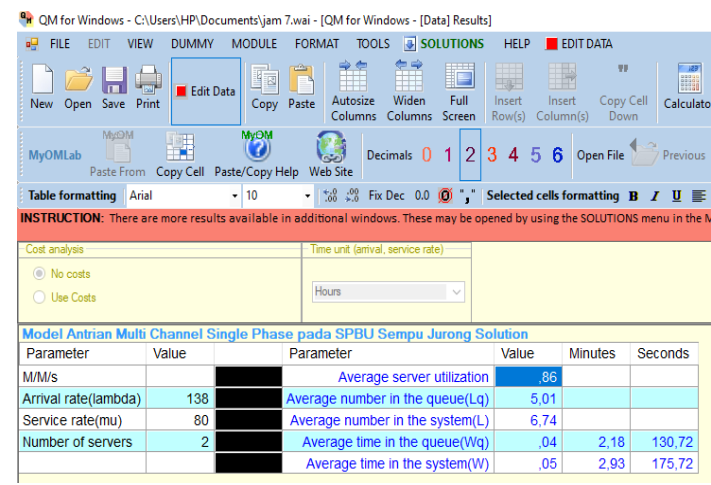

Gambar 4. Hasil Perhitungan Antrian Menggunakan POM-QM for Windows 5.2 untuk Jam 07.00-08.00

2. Hasil perhitungan untuk jam 16.00-17.00

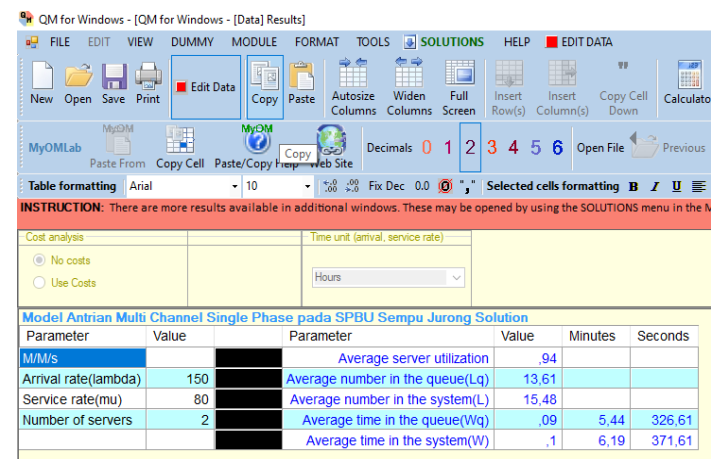

Gambar 5. Hasil Perhitungan Antrian

Menggunakan POM-QM for Windows 5.2 untuk Jam 16.00-17.00

3. Hasil perhitungan untuk jam 19.00-20.00

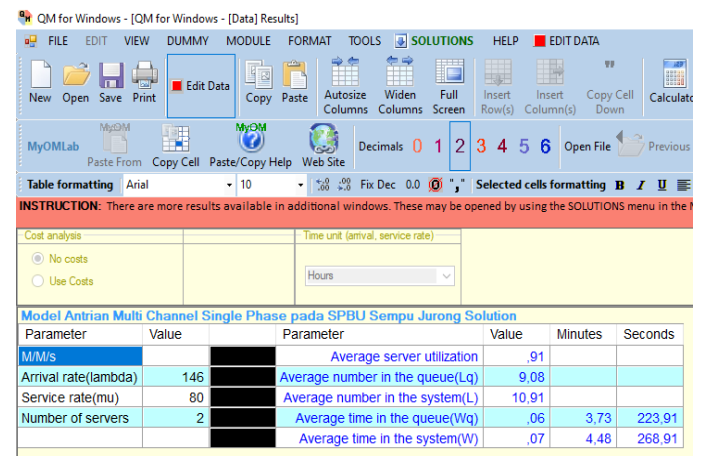

Gambar 6. Hasil Perhitungan Antrian

Menggunakan POM-QM for Windows 5.2 untuk Jam 19.00-20.00

Berdasarkan hasil analisis perhitungan secara 


\author{
Jurnal Pendidikan dan Aplikasi Industri (UNISTEK) \\ Vol. 8 No.1 Februari 2021 \\ p- ISSN : 0126 - 4036 \\ e- ISSN : 2716 - 0416
}

manual dan menggunakan software POM-QM for Windows 5.2, dapat diketahui tingkat kedatangan kendaraan roda dua di SPBU Sempu Jurong berbedabeda, standar waktu pelayanan yang ditetapkan sebesar 45 detik dan tingkat pelayanan sebesar 80 kendaraan roda dua per jam. Dengan fasilitas pelayanan sebanyak 2 buah, jumlah kendaraan roda dua yang menunggu dalam sistem $\left(\mathrm{L}_{\mathrm{s}}\right)$ tertinggi yaitu pada jam 16.00-17.00 sekitar 15 atau 16 kendaraan roda dua, waktu terpanjang yang digunakan pelanggan kendaraan roda dua menunggu dalam sistem $\left(\mathrm{W}_{\mathrm{s}}\right)$ terjadi saat jam 16.00-17.00 selama 6,19 menit, jumlah kendaraan roda dua dalam antrian $\left(\mathrm{L}_{\mathrm{q}}\right)$ tertinggi saat jam 16.00-17.00 sebanyak 14 kendaraan roda dua serta waktu terpanjang yang digunakan pelanggan untuk mengantri dalam antrian $\left(\mathrm{W}_{\mathrm{q}}\right)$ saat jam 16.00-17.00 sebesar 5,44 menit. Hal ini menunjukkan kinerja pelayanan SPBU Sempu Jurong Cikarang Utara tidak optimal, karena standar waktu pelayanan (Wq) 5,44 menit tidak sesuai dengan waktu standar yang telah ditetapkan SPBU Sempu Jurong.

Untuk mengoptimalkan tingkat pelayanan SPBU Sempu Jurong serta mengurangi gap waktu pelayanan antara standar waktu pelayanan (Wq) dengan SOP waktu yang ditetapkan SPBU Sempu Jurong sebesar 4,69 menit, dapat dilakukan dengan penambahan 1 fasilitas pelayanan menjadi 3 fasilitas pengisian bahan bakar umum untuk kendaraan roda dua. Berikut merupakan tabel hasil perhitungan analisis antrian pada SPBU Sempu Jurong Cikarang Utara dengan 3 fasilitas pelayanan menggunakan software POM-QM for Windows 5.2.

Tabel 4. Hasil Analisis Sistem Antrian SPBU Sempu Jurong dengan 3 Fasilitas

\begin{tabular}{cccccc}
\hline Periode & \multicolumn{5}{c}{ Hasil Kinerja Sistem Antrian } \\
\cline { 2 - 6 } Waktu & $\mathrm{P}_{0}$ & $\mathrm{~L}_{\mathrm{s}}$ & $\begin{array}{c}\mathrm{W}_{\mathrm{s}} \\
(\mathrm{mnt})\end{array}$ & $\mathrm{L}_{\mathrm{q}}$ & $\begin{array}{c}\mathrm{W}_{\mathrm{q}} \\
(\mathrm{mnt})\end{array}$ \\
\hline $07.00-$ & 0,161 & 2,162 & 0,96 & 0,437 & 0,18 \\
08.00 & & & & & \\
$16.00-$ & & & & & \\
17.00 & 0,132 & 2,521 & 1,02 & 0,646 & 0,06 \\
$19.00-$ & & & & & \\
20.00 & 0,141 & 2,393 & 0,96 & 0,568 & 0,24 \\
\hline
\end{tabular}

Berdasarkan Tabel 4 terlihat perubahan yang signifikan dengan adanya penambahan satu jalur fasilitas pengisian bahan bakar kendaraan roda dua untuk SPBU Sempu Jurong. Hasil analisis perhitungan menunjukkan rata-rata jumlah pelanggan kendaraan roda dua dalam sistem $\left(\mathrm{L}_{\mathrm{s}}\right)$ sebanyak 2 sampai 3 kendaraan, jumlah pelanggan kendaraan roda dua dalam antrian sebanyak 1 kendaraan, waktu tunggu pelanggan dalam sistem $\left(\mathrm{W}_{\mathrm{s}}\right)$ sekitar 0,96-1,02 menit, dan waktu tunggu pelanggan kendaran roda dua dalam antrian (Wq) sekitar 0,06-0,24 menit. Hal ini menunjukkan perhitungan di atas sudah optimal karena standar waktu pelayanan (Wq) 0,24 menit sudah jauh lebih cepat dari standar waktu yang ditetapkan sebesar 0,75 menit dan jumlah pelanggan kendaraan roda yang mengantri dalam antrian dapat dikurangi sehingga kepuasan pelanggan akan pelayanan yang diberikan SPBU Sempu Jurong Cikarang Utara dapat tercapai.

\section{Kesimpulan}

Berdasarkan hasil analisis perhitungan yang dilakukan pada SPBU Sempu Jurong, dapat ditarik kesimpulan diantaranya yaitu:

1. Fasilitas pelayanan untuk SPBU Sempu Jurong Cikarang Utara yang optimum berjumlah 3 fasilitas pelayanan.

2. Kinerja sistem pelayanan pada SPBU Sempu Jurong Cikarang Utara dengan 2 fasilitas dinilai kurang optimal, karena standar waktu pelayanan $\left(\mathrm{W}_{\mathrm{q}}\right)$ sebesar 5,44 menit tidak sesuai dengan standar waktu yang ditetapkan perusahaan yaitu sebesar 0,75 menit. Berdasarkan perhitungan metode antrian Multi Channel Single Phase secara manual dan menggunakan POM-QM for Windows 5.2, diperoleh standar waktu pelayanan $\left(\mathrm{W}_{\mathrm{q}}\right)$ yang optimal dengan penambahan fasilitas pelayanan menjadi 3 fasilitas, membutuhkan waktu sebesar 0,24 menit. Penambahan fasilitas ini merupakan cara agar pelayanan pengisian bahan bakar SPBU Sempu Jurong untuk kendaraan roda dua meningkat dan dapat segera diselesaikan sehingga pelanggan tidak membutuhkan waktu lama untuk mengantri. Kinerja sistem antrian pada SPBU Sempu Jurong Cikarang Utara masih perlu ditingkatkan lagi dari berbagai segi baik dari segi fasilitas, karyawan, kebersihan dan keamanan agar pelanggan merasa puas akan sistem pelayanan SPBU Sempu Jurong.

\section{Daftar Pustaka}

Basuki, M. (2018). Analisis Sistem Antrian Pelayanan Registrasi Mahasiswa di Universitas Tridinanti Palembang. Jurnal Sistem dan Manajemen Industri.

Febrianti, T. (2020). Analisis Sistem Antrian pada Customer Service Representative (CSR) di PT. Telkom Indonesia Kandatel Bandung. Jurnal Indonesia Membangun.

Hanggara, F. D., \& Putra, R. D. (2020). Analisis Sistem Antrian Pelanggan SPBU dengan Pendekatan Simulasi Arena. Jurnal INTECH.

Manalu, C., \& Palandeng, I. (2019). Analisis Sistem Antrian Sepeda Motor pada Stasiun 
Pengisian Bahan Bakar Umum (SPBU) 74.951.02 Malalayang. Jurnal EMBA, 551560.

Nengsih, M. K., \& Yustanti, N. V. (2017). Analisis Sistem Antrian Pelayanan Administrasi Pasien Rawat Jalan pada Rumah Sakit Padmalalita Muntilan. Jurnal Ilmiah Manajemen.

Oktrima, B. (2017). Analisis Antrian di Kasir Hypermart Mall WTC Matahari Serpong. Jurnal Ilmiah Ilmu Manajemen (INOVASI), $1-12$.

Permatasari, E., \& Suryowati, K. (2020). Analisis Sistem Antrian Multiphase pada Fasilitas Pelayanan Masyarakat Bidang Pendaftaran Penduduk di Dinas Kependudukan dan Pencatatan Sipil Kabupaten Madiun. Jurnal Statistika Industri dan Komputasi.

Raharjo, K., \& Nurhajati, H. (2018). Analisis Teori Antrian dengan Multi channel (M/M/c) pada Stasiun Pengisian Bahan Bakar Umum (SPBU) (Studi Kasus SPBU Soekarno Hatta Malang). e-Jurnal Riset Manajemen.

Saputra, T. T., Irawan, B., \& Ilhamsyah. (2017). Aplikasi Antrian Nasabah Bank Menggunakan Teks dan Suara Bebasis Jaringan Wireless Local Area Network (WLAN). Jurnal Coding Sistem Komputer Universitas Tanjungpura, 1-7.

Sari, N. S. (2013). Analisis Teori Antrian pada Stasiun Pengisian Bahan Bakar Umum (SPBI) Gajah Mada Jember. Jember: Universitas Jember.

Setiawati, C. I., \& Budyanna, F. A. (2017). Qounting Teller Quantity For Better Queue in Financial Institution: Case of Bank Central Asia, Metro Indah Mall Branch Office-Bandung. Jurnal Bisnis dan Manajemen, 65-72.

Supriyadi, Alfarisi, S., Karno, R., \& Cahyadi, D. (2019). Queue Design of Bank Teller Service in Banten, Indonesia. 165-171.

Widiantono, E., \& Sukmono, T. (2017). Analisis Antrian Service Motor di Dealer Resmi Honda. Jurnal PROZIMA. 